\title{
Terminal Sliding Mode Control with Adaptive Feedback Control in a Class of Chaotic Systems
}

\author{
Degang Yang and Guoying Qiu \\ College of Computer and Information Science, Chongqing Normal University, Chongqing 401331, China \\ Correspondence should be addressed to Degang Yang; 460494731@qq.com
}

Received 1 May 2014; Accepted 22 June 2014; Published 13 July 2014

Academic Editor: Chuandong Li

Copyright (C) 2014 D. Yang and G. Qiu. This is an open access article distributed under the Creative Commons Attribution License, which permits unrestricted use, distribution, and reproduction in any medium, provided the original work is properly cited.

\begin{abstract}
This paper analyzes semifinite time stability for a general chaotic system. By cooperating methods terminal sliding mode (TSM) with adaptive feedback control (AFC), a controller based on the two methods is derived to achieve semifinite time stability. The theoretical analysis employs the theories of linear matrix inequalities and Lyapunov functional method. Finally, numerical simulation is given to illustrate the derived theoretical results.
\end{abstract}

\section{Introduction}

Chaos phenomenon can be found in many physics and engineering systems in practice. However, to improve the system's performance, it is often desirable to avoid chaos, and various methods are proposed. Due to different emphases, controllers have different merits and drawbacks. For example, TSM establishes terminal sliding mode surface to couple system variables and control them to reach equilibrium points. Its control is effective, but it can only control system states coupled in the sliding mode surface; readers are referred to [1-7] for more detailed information. As for impulse control [8-16], they add impulse effects to continuous differential equation and, by constructing comparison system, establish relationships between parameters of system and impulse. Their controllers are effective, but design processes of their controllers are too much complex. For adaptive feedback control as in [17-21], similar to TSM, they have unified the format with different parameters. AFC has a wide range of applications in various fields, but its dynamic is not as good as the first two.

For the system's structure constructed in this paper, we design controllers from methods TSM and AFC, both of which have unified formats. If TSM is used only, we should design several TSM surfaces. If AFC is used only, its controller is very simple and flexible, but it can only achieve asymptotical stability. Combining their merits and drawbacks, a cooperative controller is proposed in the paper. TSM method finite-timely controls system states, which are coupled in TSM surface, as in [4-7]. Simple AFC is introduced as a supplementary control into the remaining states of the system, controlling system states which are outside TSM surface and making them asymptotically stable $[18,20]$, and, finally, the overall system tends to be semifinitetime stable [5].

This design scheme can control main elements of system finite-time stability, firstly, then use AFC method to ensure that other dimensions are asymptotically stable, and finally realize the overall system's semifinite time stability. Compared with TSM only, this design can greatly reduce the control input and simplify the design process of controller; compared with $\mathrm{AFC}$ only, it has obvious advantages in time sequence.

The rest of the paper is organized as follows. In Section 2, a general chaotic system model and some preliminaries are presented. In Section 3, we will show theoretical analysis, establish several sufficient conditions for SFTS, and formulate controller. In Section 4, numerical simulation is presented to verify the validity of theoretical results. Finally, the conclusions are drawn in Section 5. 


\section{Problem Statement and Preliminaries}

We use the following differential equation to describe general dynamic chaos system:

$$
\dot{y}=f(y) .
$$

In this paper, we are committed to solve the stability analysis of chaotic systems which can be organized into the following form:

$$
\begin{gathered}
\dot{x}_{1}=A_{11} x_{1}+A_{12} x_{2} \\
\dot{x}_{2}=A_{21} x_{1}+A_{22} x_{2}+f_{2}\left(x_{1}, x_{2}, x_{3}\right) \\
\dot{x}_{3}=f_{3}\left(x_{1}, x_{2}, x_{3}\right),
\end{gathered}
$$

where $x_{1}=\left(y_{1}, \ldots, y_{r}\right)^{T} x_{2}=\left(y_{r+1}, \ldots, y_{s}\right)^{T} x_{3}=\left(y_{s+1}, \ldots\right.$, $\left.y_{t}\right)^{T}, f_{2} f_{3}$, are nonlinear part.

Definition 1 (finite-time stability [22, 23]). Consider that $x(t) \in R^{n}$ are system states. If there exists constant $T>0$, such that $\lim _{t \rightarrow T}\|x\|=0$ and if $t \geq T,\|x(t)\|=0$, then the system realizes finite-time stability.

Definition 2 (semifinite-time stability [5]). Take dynamic system (2), for example; after adding controllers, if the states $x_{1}$ and $x_{2}$ are finite-time stable and the states $x_{3}$ are asymptotically stable, then we call the system semifinite-time stable.

Lemma 3 (see [23]). Assume that a continuous, positive-definite function $V(t)$ satisfies the following differential inequality:

$$
\dot{V}(t) \leq-c V^{\tau}(t), \quad \forall t \geq t_{0}, V\left(t_{0}\right) \geq 0,
$$

where $c>0,0<\tau \leq 1$ are two constants. Then, for any given $t_{0}, V(t)$ satisfies the following results. $V(t) \equiv 0, \forall t \geq t_{1}$ with $t_{1}$ being given by

$$
t_{1}=t_{0}+\frac{V^{1-\tau}\left(t_{0}\right)}{c(1-\tau)} .
$$

Assumption 4. Assume that there exist positive constants $l_{k}(k=1, \ldots, m), f_{2}, f_{3}$ satisfying

$$
\|f(x)\| \leq \sum_{k=1}^{m} l_{k}\|x\|^{k}, \quad\|x\|=\max \left|y_{i}\right|,(i=s+1, \ldots, t) .
$$

\section{Main Results}

In this section, controller is designed from TSM and AFC separately with detailed theoretical analysis. TSM portion is used to derive $x_{1} x_{2}$ finite-time stability, and AFC is for asymptotical stability of $x_{3}$. Finally, system (2) tends to semifinite time stability.

3.1. Terminal Sliding Mode Portion Design. Take the system's first two parts of the states and add controlling part:

$$
\begin{gathered}
\dot{x}_{1}=A_{11} x_{1}+A_{12} x_{2} \\
\dot{x}_{2}=A_{21} x_{1}+A_{22} x_{2}+f_{2}\left(x_{1}, x_{2}, x_{3}\right)+u_{1} .
\end{gathered}
$$

Generally speaking, the process of terminal sliding mode control can be divided into two stages: the first stage is to establish the nonsingular terminal sliding model surface; the second is to design TSM controller, which can make the system variables reach and maintain the TSM surface within finite time.

So in this paper, a nonsingular TSM surface is introduced as follows:

$$
s=C_{1} x_{1}+C_{2} x_{2}+C_{3} x_{1}^{q / p},
$$

where parameters $C_{1}, C_{2}, C_{3}, 0<q<p$ are odd matrices determined by the designer.

Theorem 5. In the system (6), we add the following controller:

$$
\begin{gathered}
u_{1}=-\frac{1}{C_{2}}\left[\left(C_{1}+C_{3} \frac{q}{p} x_{1}^{(q-p) / p}\right)\left(A_{11} x_{1}+A_{12} x_{2}\right)\right] \\
-\left(A_{21} x_{1}+A_{22} x_{2}+f_{2}\left(x_{1}, x_{2}, x_{3}\right)\right)-\frac{\psi s}{C_{2}} \\
\psi=\mu+\eta\|s\|^{\xi-1},
\end{gathered}
$$

where $\mu>0, \eta>0$, and $0<\xi<1$. Then the system states slide on the switch surface $s=0$.

Proof. Introduce the following Lyapunov function:

$$
V_{1}=\frac{1}{2} s^{T} s
$$

Differentiating the function along the trajectories of $s$, we will obtain

$$
\begin{aligned}
\dot{V}_{1}= & s^{T} \dot{s} \\
= & s^{T}\left(C_{1}+C_{3} \frac{q}{p} x_{1}^{(q-p) / p}\right)\left(A_{11} x_{1}+A_{12} x_{2}\right) \\
& +s^{T} C_{2}\left(A_{21} x_{1}+A_{22} x_{2}+f_{2}\left(x_{1}, x_{2}, x_{3}\right)\right)+s^{T} u_{1} \\
= & -s^{T} \psi s \\
= & -\mu s^{T} s-\eta\|s\|^{\xi+1} \\
\leq & -\eta\|s\|^{\xi+1} \\
\leq & -2^{(\xi+1) / 2} \eta V_{1}^{(\xi+1) / 2} .
\end{aligned}
$$

From Lemma 3 and Definition 1, TSM surface could reach the equilibrium point within finite time.

When the system states slide on the switch surface $s=0$, they satisfy the following equations:

$$
\begin{aligned}
& s=0, \\
& \dot{s}=0 .
\end{aligned}
$$

Then

$$
x_{2}=-C_{2}^{-1}\left(C_{1} x_{1}+C_{3} x_{1}^{q / p}\right)
$$


Thus, we can get the following sliding mode dynamics:

$$
\dot{x}_{1}=\left(A_{11}-A_{12} C_{1} C_{2}^{-1}\right) x_{1}-A_{12} C_{3} C_{2}^{-1} x_{1}^{q / p} .
$$

Theorem 6. For differential equation (13), if there exist a positive symmetric matrix $P$ and matrices $C_{1} C_{2}$, introduced in (7), satisfying the following conditions:

$$
\begin{gathered}
P\left(A_{11}-A_{12} C_{1} C_{2}^{-1}\right)+\left(A_{11}-A_{12} C_{1} C_{2}^{-1}\right)^{T} P<0 \\
P A_{12} C_{3} C_{2}^{-1}=\operatorname{diag}\left\{b_{i}\right\}, \quad b_{i}>0, i=1, \ldots, r, \\
b=\min \left\{b_{i}\right\},
\end{gathered}
$$

then the system (6) is finite-time stable.

Proof. Introduce the following Lyapunov function:

$$
V_{2}=x_{1}^{T} P x_{1}
$$

where $P$ is a symmetric positive definite matrix satisfying the conditions in (14).

It can be proved easily that

$$
\left\|x_{1}\right\| \geq \sqrt{\frac{V\left(x_{1}\right)}{\lambda}}, \quad \lambda=\lambda_{\max }(P),
$$

where $\lambda_{\max }(P)$ is the maximum eigenvalue of $P$.

Calculate its derivative along the solution of system (13) and we can obtain

$$
\begin{aligned}
\dot{V}_{2}= & 2 x_{1}^{T} P \dot{x}_{1} \\
= & 2 x_{1}^{T} P\left[\left(A_{11}-A_{12} C_{1} C_{2}^{-1}\right) x_{1}-A_{12} C_{3} C_{2}^{-1} x_{1}^{q / p}\right] \\
= & x_{1}^{T}\left[P\left(A_{11}-A_{12} C_{1} C_{2}^{-1}\right)+\left(A_{11}-A_{12} C_{1} C_{2}^{-1}\right)^{T} P\right] x_{1} \\
& -2 x_{1}^{T} P A_{12} C_{3} C_{2}^{-1} x_{1}^{q / p} \\
\leq & -2 \sum_{i=1}^{r} b_{i}\left(x_{1 i}^{2}\right)^{(q+p) / 2 p} \\
\leq & -2 b\left\|x_{1}\right\|^{(p+q) / p} \\
\leq & -\frac{2 b}{\lambda^{(q+p) / 2 p}} V\left(x_{1}\right)^{(q+p) / 2 p} .
\end{aligned}
$$

where $\beta_{k}(k=1, \ldots, m)$ are adaptive parameters whose adaptive laws are

$$
\dot{\beta}_{k}=-\sum_{j=1}^{n} \gamma_{k j} x^{2(j+k)-2}
$$

Then, the controlled system changes into the following form:

$$
\dot{x}=f(x)+u_{2}
$$

and it is asymptotically stable.

Proof. We introduce the following Lyapunov function:

$$
V_{3}=\frac{1}{2} \sum_{j=1}^{n} \frac{1}{j} x^{2 j}+\frac{1}{2} \sum_{k=1}^{m} \frac{1}{\gamma_{k}}\left(\beta_{k}+L\right)^{2}
$$

where $L$ is a constant bigger than the maximum of

$$
\begin{gathered}
{\left[\frac{m}{2}\right]+l_{2 k-1} \quad\left(k=1,2, \ldots,\left[\frac{m+1}{2}\right]\right),} \\
{\left[\frac{m}{2}\right]+\frac{n l_{2 k}^{2}}{4} \quad\left(k=1,2, \ldots,\left[\frac{m}{2}\right]\right),}
\end{gathered}
$$

where $[m / 2]$ denotes the largest integer, no more than $m / 2$.

The derivative of $V_{3}$ along trajectories of (23) is

$$
\begin{aligned}
\dot{V}_{3}= & \sum_{j=1}^{n} x^{2 j-1} \dot{x}+\sum_{k=1}^{m} \frac{1}{\gamma_{k}}\left(\beta_{k}+L\right) \dot{\beta}_{k} \\
\leq & \sum_{j=1}^{n}|x|^{2 j-1} \sum_{k=1}^{m} l_{k}\|x\|^{k}-L \sum_{k=1}^{m} \sum_{j=1}^{n}|x|^{2(j+k)-2} \\
= & \sum_{j=1}^{n} \sum_{k=1}^{[(m+1) / 2]}|x|^{2 j-1} l_{2 k-1}\|x\|^{2 k-1}+\sum_{j=1}^{n} \sum_{k=1}^{[m / 2]}|x|^{2 j-1} l_{2 k}\|x\|^{2 k} \\
& -L \sum_{j=1}^{n} \sum_{k=1}^{m}|x|^{2(j+k)-2} \\
\leq & \sum_{j=1}^{n}\left[\sum_{k=1}^{[(m+1) / 2]} l_{2 k-1}|x|^{2(j+k)-2}+\sum_{j=1}^{n} \sum_{k=1}^{[m / 2]}|x|^{4 j-2}\right. \\
& +\sum_{j=1}^{n} \sum_{k=1}^{[m / 2]} \frac{l_{2 k}^{2}}{4}|x|^{4 k}-L \sum_{j=1}^{n} \sum_{k=1}^{m}|x|^{2(j+k)-2}
\end{aligned}
$$




$$
\begin{aligned}
\leq & \sum_{j=1}^{n} \sum_{k=1}^{[(m+1) / 2]} l_{2 k-1}|x|^{2(j+k)-2}+\left[\frac{m}{2}\right] \sum_{j=1}^{n} \sum_{k=1}^{m}|x|^{2(j+k)-2} \\
& +\frac{n l_{2 k}^{2}}{4} \sum_{j=1}^{n} \sum_{k=1}^{[m / 2]}|x|^{2(j+k)-2}-L \sum_{j=1}^{n} \sum_{k=1}^{m}|x|^{2(j+k)-2} \\
\leq & -\sum_{k=1}^{[(m+1) / 2]}\left(L-\left[\frac{m}{2}\right]-l_{2 k-1}\right) \sum_{j=1}^{m}|x|^{2(j+k)-2} \\
& -\sum_{k=1}^{[m / 2]}\left(L-\left[\frac{m}{2}\right]-\frac{n l_{2 k}^{2}}{4}\right) \sum_{j=1}^{m}|x|^{2(j+k)-2} \\
\leq & 0 .
\end{aligned}
$$

So if and only if $x=0, \dot{V}_{3}=0$, then asymptotical stability of (22) is proved.

Remark 8. Add related terms of $i$ to prove course; introduce Lyapunov function:

$$
\begin{aligned}
V= & \frac{1}{2} \sum_{i=s+1}^{t} \sum_{j=1}^{n} \frac{1}{j} y_{i}^{2 j} \\
& +\frac{1}{2 \gamma_{k i}} \sum_{i=s+1}^{t} \sum_{k=1}^{m}\left(\beta_{k i}+L\right)^{2}
\end{aligned}
$$

by the same method and almost the same process; we can prove the globally asymptotical stability of system state (18) with AFC controller. So AFC acts as a single-state control and also can be designed globally.

\section{Simulation Results}

After the theoretical analyses are investigated, we discuss the following numerical example to illustrate the derived theoretical results. From [13], we can obtain the system model of Chua's Oscillator:

$$
\begin{gathered}
\dot{x}_{1}=\alpha\left(-x_{1}+x_{2}-f\left(x_{1}\right)\right), \\
\dot{x}_{2}=x_{1}-x_{2}+x_{3}, \\
\dot{x}_{3}=-\beta x_{2}-\gamma x_{3},
\end{gathered}
$$

where $f\left(x_{1}\right)=b x_{1}+((a-b) / 2)\left(\left|x_{1}+1\right|-\left|x_{1}-1\right|\right)$.

The Chua oscillator is illustrated in Figures 1 and 2. For simulation, the system parameters are used as $\alpha=8.72, \beta=$ 14.29, $\gamma=0.01, a=-8 / 7, b=-5 / 7$, with initial conditions $\left(x_{1}\left(t_{0}\right), x_{2}\left(t_{0}\right), x_{3}\left(t_{0}\right)\right)^{T}=(-2.1213,-0.0662,2.8811)^{T}$.

With constraint condition (14), we get $C_{1}=2, C_{2}=C_{3}=$ 1 , introduced from (7); we take $\mu=\eta=10, \xi=1 / 2$, in (9); via (8), obtain $u_{1}$, added to system (6). Its effectiveness is shown in Figure 3. After the convergence of $x_{1}, x_{2}$, there is only $\dot{x}_{3}=-0.01 x_{3}$ in (18). So we let $m=1, n=2$, and $\gamma_{k j}=1$; in (20) and (21), get $u_{2}$, added to system (22). Its effectiveness is shown in Figure 4.

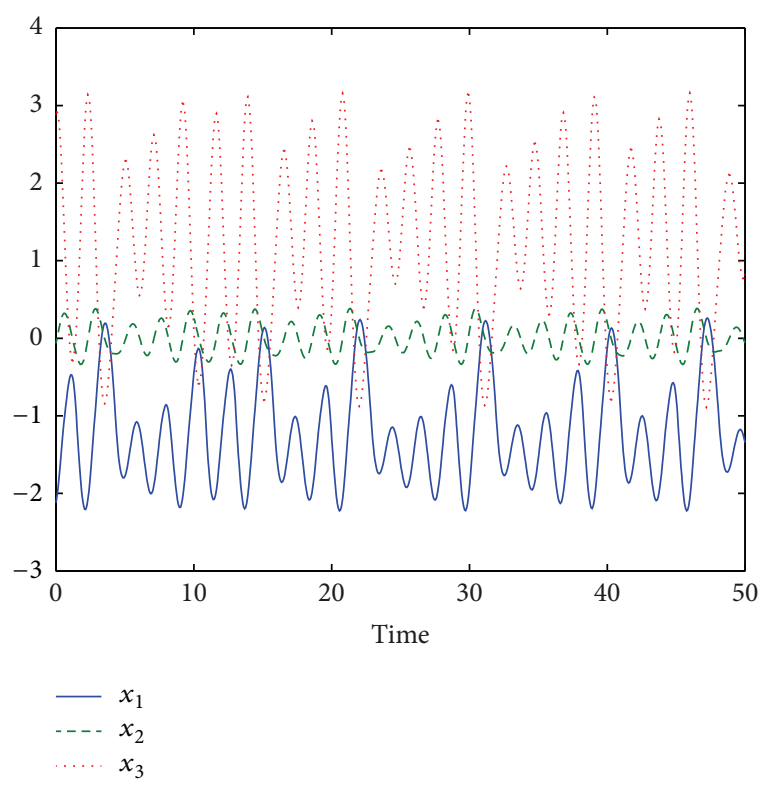

Figure 1: The time series of uncontrolled Chua oscillator.

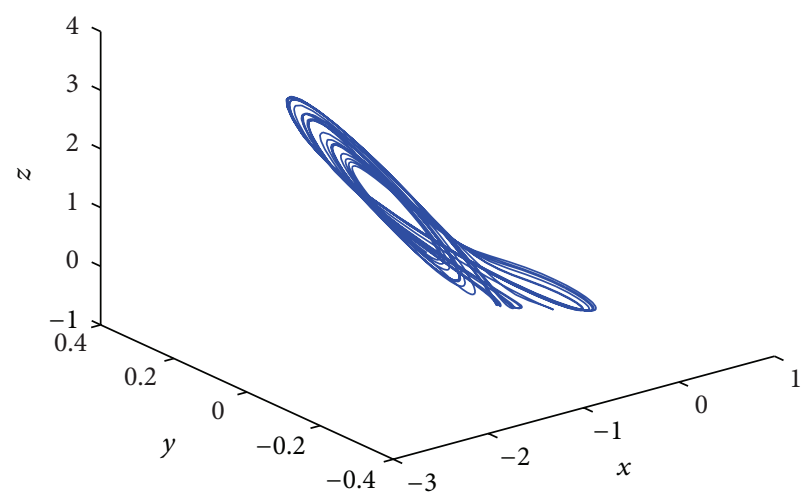

FIgURE 2: Chaotic attractor of uncontrolled Chua oscillator.

According to simulation results, it is easy to find that, the TSM method can effectively control the first two of system states and realize their finite-time stability. Comparing Figures 3 and 4, we can find that AFC controller effectively controls the remaining one of system state and makes it asymptotically stable. Finally, system states globally tend to semifinite time stable and we complete the expected objectives.

\section{Conclusions}

A controller, cooperating TSM with AFC, is proposed to control a class of chaotic system as described above in this paper. Two methods are complementary in the procedure and finally achieve good effectiveness. Complex TSM method controls main elements of chaotic system to finite-time stability; then, simple AFC method controls dimension elements of chaotic system to asymptotic stability and finally the overall system goes to semifinite time stability. This design scheme can not only guarantee the system's convergence but also 


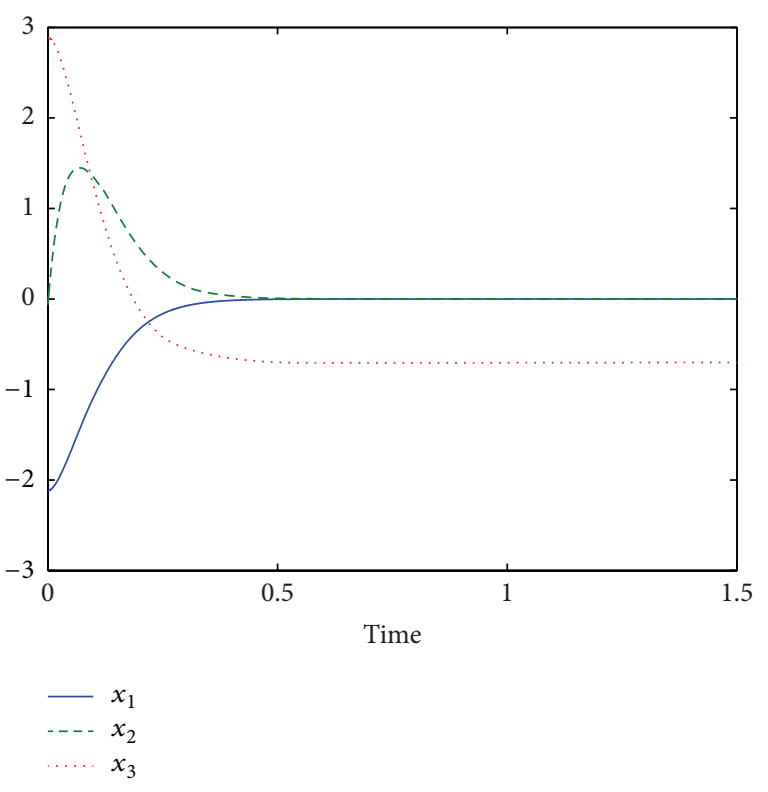

FIGURE 3: Time series of Chua oscillator with TSM only.

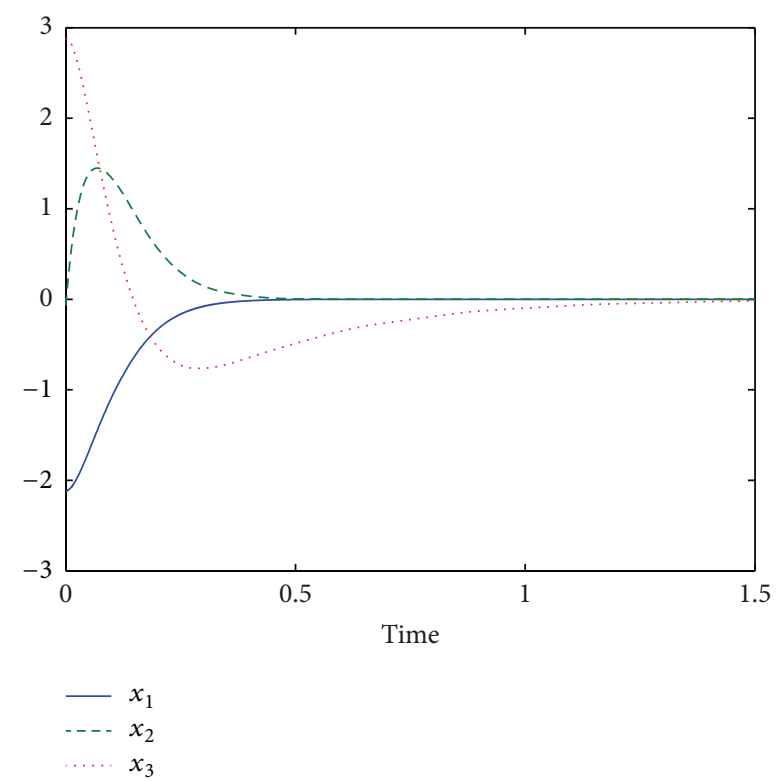

FIgURE 4: Time series of Chua oscillator with both TSM and AFC.

reduce the system's control-input spending and also further improve their applications in chaos control.

In this paper, effective performance of the simulation results proves the feasibility of this design scheme. The proposed method can be applied in many famous chaotic systems such as Lorenz, liu chaotic system, and Chua's circuit.

\section{Conflict of Interests}

The authors declare that there is no conflict of interests regarding the publication of this paper.

\section{Acknowledgments}

The authors are greatly indebted to the anonymous referees for their constructive comments. The work described in this paper was partially supported by the National Natural Science Foundation of China (no. 10971240), the Natural Science Foundation Project of CQ CSTC (nos. cstc2012jjA40052, cstc2013jcyjA0973, and cstc2013jcyjA80013), Applying Basic Research Program of Chongqing Education Committee (nos. KJ120615, KJ120630, KJ130611, and KJ1400505), the Foundation Project of Chongqing Normal University (no. 13XLZ01), and the Program of Chongqing Innovation Team Project in University under Grant no. KJTD201308.

\section{References}

[1] Y. Feng, X. Yu, and Z. Man, "Non-singular terminal sliding mode control of rigid manipulators," Automatica, vol. 38, no. 12, pp. 2159-2167, 2002.

[2] Z. Man and X. Yu, "Terminal sliding mode control of MIMO linear systems," in Proceedings of the 35th IEEE Conference on Decision and Control, vol. 4, IEEE, 1996.

[3] X. Yu and M. Zhihong, "Fast terminal sliding-mode control design for nonlinear dynamical systems," IEEE Transactions on Circuits and Systems I: Fundamental Theory and Applications, vol. 49, no. 2, pp. 261-264, 2002.

[4] H. Wang, X. Zhang, X. Wang, and X. Zhu, "Finite time chaos control for a class of chaotic systems with input nonlinearities via TSM scheme," Nonlinear Dynamics, vol. 69, no. 4, pp. 19411947, 2012.

[5] Z. Yang and D. Xu, "Stability analysis and design of impulsive control systems with time delay," IEEE Transactions on Automatic Control, vol. 52, no. 8, pp. 1448-1454, 2007.

[6] Z. Yang and D. Xu, "Stability analysis of delay neural networks with impulsive effects," Dynamics of Continuous, Discrete \& Impulsive Systems A, vol. 13, no. 5, pp. 563-573, 2006.

[7] Y. Zhao and J. Wang, "Exponential synchronization of impulsive complex networks with output coupling," International Journal of Automation and Compution, vol. 10, no. 4, pp. 350-359, 2013.

[8] X. Lou, Q. Ye, and B. Cui, "Impulsive stabilization of fuzzy neural networks with time-varying delays," Arabian Journal of Mathematics, vol. 2, no. 1, pp. 65-79, 2013.

[9] H. Wang and C. Ding, "A new nonlinear impulsive delay differential inequality and its applications," Journal of Inequalities and Applications, vol. 2011, article 11, 2011.

[10] D. Wang and Y. Zheng, "Stabilizing a class of chaotic systems by using adaptive feedback control," Physics Procedia, vol. 24, pp. 1922-1927, 2012.

[11] V. I. Utkin, "Sliding mode control design principles and applications to electric drives," IEEE Transactions on Industrial Electronics, vol. 40, no. 1, pp. 23-36, 1993.

[12] Y. Hong, G. Yang, L. Bushnell, and H. O. Wang, "Global finitetime stabilization: from state feedback to output feedback," in Proceedings of the 39th IEEE Confernce on Decision and Control, pp. 2908-2913, Sydney, Australia, December 2000.

[13] Y. Yu and J. Yu, Impulsive modeling and stability study on nonlinear circuits and systems, [Ph.D. thesis], Electronic Science and Technology University, 2008.

[14] R. Palm, "Sliding mode fuzzy control," in Proceedings of the IEEE Conference on Fuzzy Systems, pp. 519-526, San Diego, Calif, USA, 1992. 
[15] Y. Wang, X. Shi, Z. Zuo, M. Z. Q. Chen, and Y. Shao, "On finite-time stability for nonlinear impulsive switched systems," Nonlinear Analysis: Real World Applications, vol. 14, no. 1, pp. 807-814, 2013.

[16] Y. Wang, G. Wang, X. Shi, and Z. Zuo, "Finite-time stability analysis of impulsive switched discrete-time linear systems: the average dwell time approach," Circuits, Systems, and Signal Processing, vol. 31, no. 5, pp. 1877-1886, 2012.

[17] M. M. El-Dessoky and M. T. Yassen, "Adaptive feedback control for chaos control and synchronization for new chaotic dynamical system," Mathematical Problems in Engineering, vol. 2012, Article ID 347210, p. 12, 2012.

[18] W. Guo and D. Liu, "Adaptive control of chaos in Chua's circuit," Mathematical Problems in Engineering, vol. 2011, Article ID 620946, 14 pages, 2011.

[19] R. Zhang and S. Yang, "Stabilization of fractional-order chaotic system via a single state adaptive-feedback controller," Nonlinear Dynamics, vol. 68, no. 1-2, pp. 45-51, 2012.

[20] M. Feki, "An adaptive feedback control of linearizable chaotic systems," Chaos, Solitons \& Fractals, vol. 15, no. 5, pp. 883-890, 2003.

[21] Q. Zhong and S. Xu, "Exponential stabilization for takagisugeno fuzzy systems with time delay via impulsive control," in Advanced Intelligent Computing, D.-S. Huang, Y. Gan, V. Bevilacqua, and J. C. Figueroa, Eds., vol. 6838 of Lecture Notes in Computer Science, pp. 619-625, Springer, Berlin, Germany, 2011.

[22] D. Xin and Y. Liu, Finite-time stability analysis and control design research [M.S. thesis], Shandong University, 2008.

[23] Y. Feng, L. Sun, and X. Yu, "Finite time synchronization of chaotic systems with unmatched uncertainties," in Proceedings of the 30th Annual Conference of the IEEE Industrial Electronics Society (IECON '04), pp. 2911-2916, Busan, Republic of Korea, November 2004. 


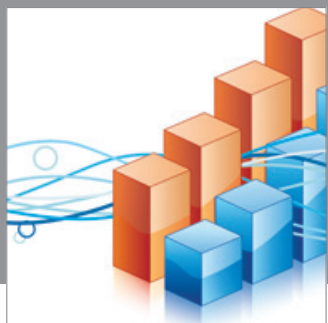

Advances in

Operations Research

mansans

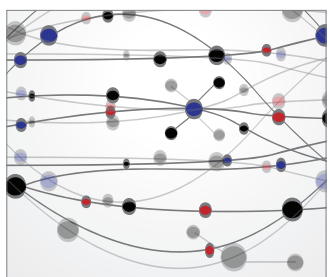

The Scientific World Journal
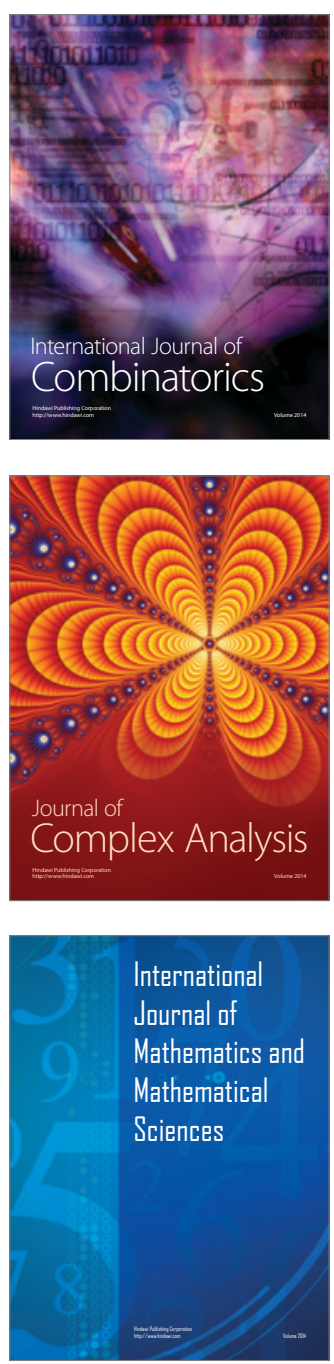
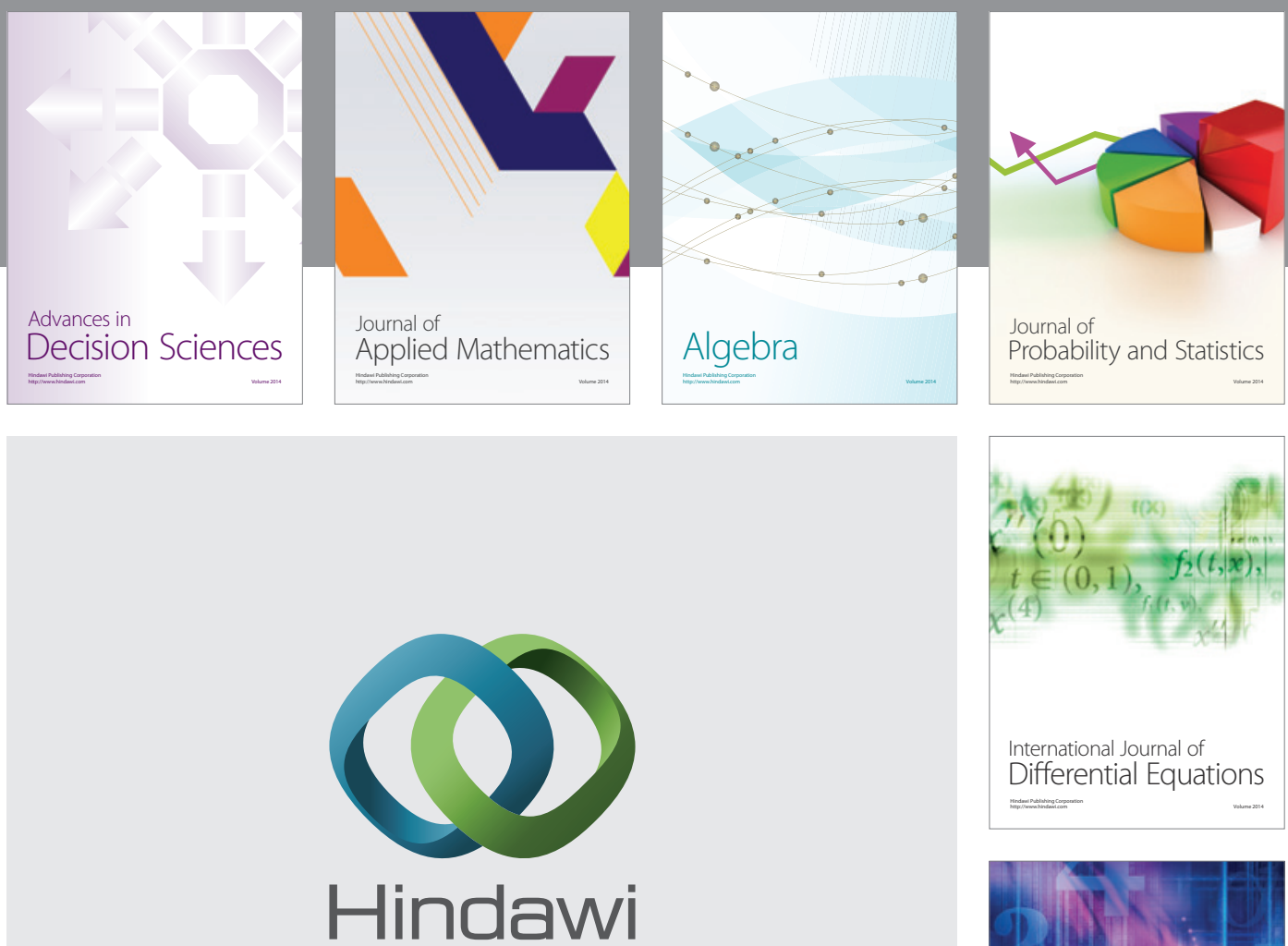

Submit your manuscripts at http://www.hindawi.com
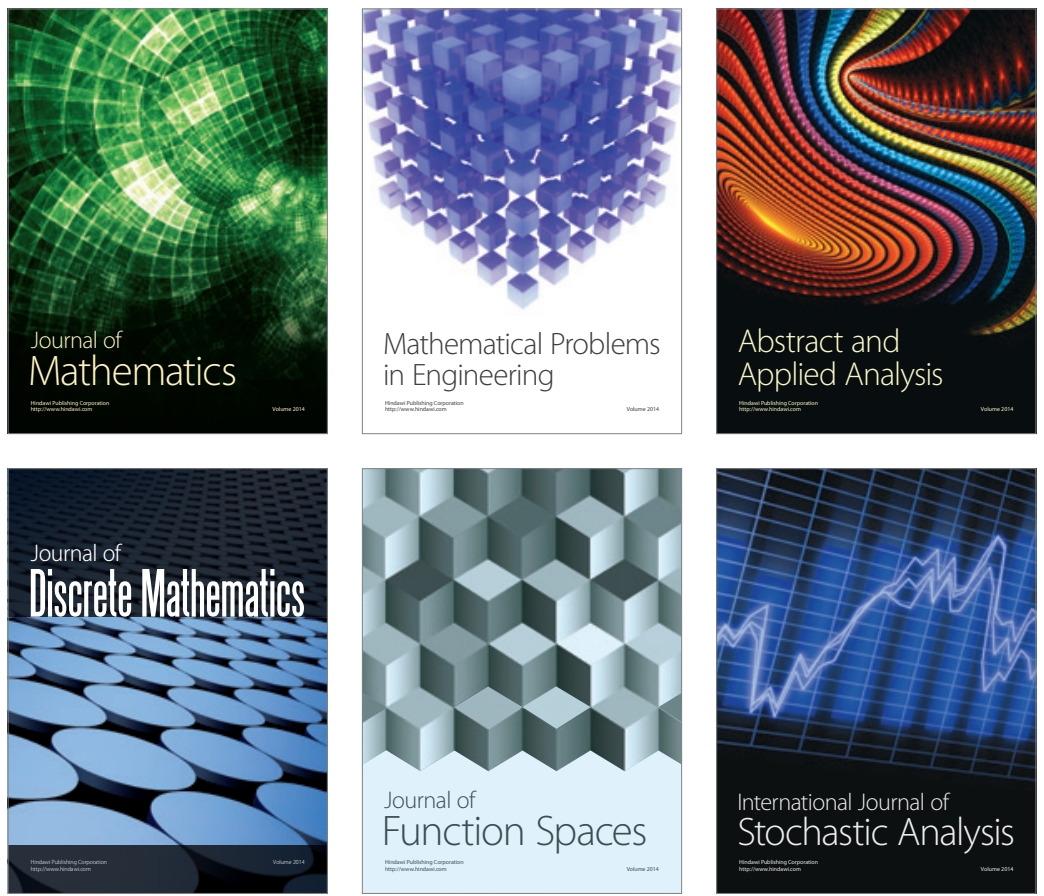

Journal of

Function Spaces

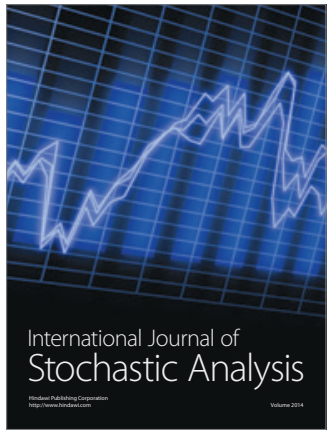

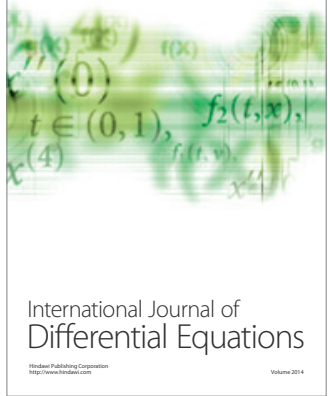
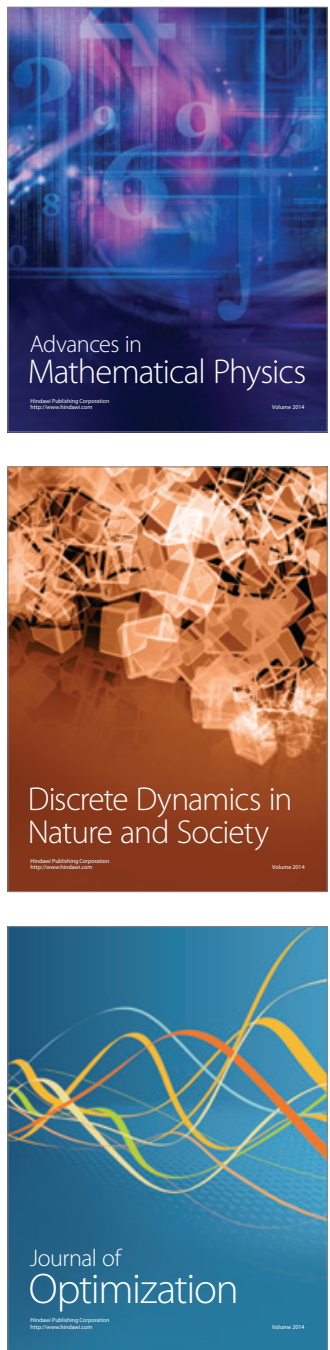